\title{
Lower Back Injuries in Rowing National Level Compared to International Level Rowers
}

\author{
Geoffrey Verrall ${ }^{1, *}$; Andrew Darcey ${ }^{2}$ \\ ${ }^{1}$ Department of SPORTMED.SA Sports Medicine Clinic, South Australian Sports Institute, Adelaide, Australia \\ ${ }^{2}$ Department of South Australian Sports Institute, Australia and Leading Edge Physical Therapy, Adelaide, Australia \\ ${ }^{*}$ Corresponding author: Geoffrey Verrall, Department of SPORTMED.SA Sports Medicine Clinic, South Australian Sports Institute, Adelaide, Australia. Tel: +61-883628111, Fax: +61- \\ 83626635, E-mail: verrallg@bigpond.com
}

Received: December 21, 2013; Accepted: July 25, 2014

\begin{abstract}
Background: Rowing injuries are common, with lower back injuries having the highest incidence.
Objectives: This study was to investigate the major rowing injuries seen at a single high performance rowing sports program overa 5 years training period and establish if any relationship exists between these injuries and the level of competition that the rower is partaking in. Patients and Methods: All rowers at the South Australian Sports Institute (SASI) programs were designated as being either international or national level rowers. Injuries that caused greater than 5 days training loss during any one training year were recorded. The number of lower back injuries and rib stress injuries causing training time loss were analysed to assess whether there was any association between the level of rower and the nature and type of injury causing training time loss.

Results: Forty-five national rowers (97 training years) had 15 lower back injuries compared to 12 international rowers 35 training years) with 1 lower back injury. Thus a national level rower was more likely to have a lower back injury compared to an international rower $\mathrm{P}=$ 0.05 . In contrast an international level was more likely to have a rib stress fracture compared to a national rower $\mathrm{P}=0.04 .21 \%$ of all injuries in this study were a consequence of cycling injuries.

Conclusions: Lower back injuries are a significant cause of training time lost in rowers. These injuries are much more likely to occur in national level rowers when compared to international level rowers. In contrast rib stress injuries are associated with international compared to national level rowers.
\end{abstract}

Keywords:Rowing; Rib; Stress fracture; Lower Back; Epidemiology

\section{Background}

The sport of rowing is an international sport with many countries having high performance programs developing rowers for competition at the Olympic Games and World Championships. As with most sports that require intensive training and effort, injuries in rowing are common. The most common injuries in rowing are as a consequence of overuse $(1,2)$. The most common overuse injuries to cause significant time loss from training in rowers are lower back and rib stress injuries $(1,3)$ with low back injuries accounting for $15-25 \%$ of all rowing injuries $(1,4,5)$. During the rowing stroke the back acts, in essence, as a cantilever and connects the power from the drive of the legs to the oars. This is similar for both sculling and ergometer rowing with additional torsional forces with sweep rowing (6). The forces on the back are reflected in an MRI study on lumbar spine abnormalities in rowers where $85 \%$ had positive MRI results for disc herniation and lumbar spine levels of degeneration compared to $20 \%$ of age matched non-rowing population (7). Rib stress fractures are, as a sports injury, almost unique to the sport of rowing. It has been stated that rib stress fractures occur more in the elite level rowers $(1,8)$ and in the year prior to the major rowing competition, the Olympics (9). However there are limited studies that report any injuries, including rib stress fracture, in lower level rowers and as a consequence, this assertion of rib stress fractures being associated with elite level rowing has not been tested. In a similar manner it has been asserted that those athletes who enter college with pre-existing back pain are more likely to have symptoms in college but less likely to miss extended training periods and nor are likely to have their rowing career injuries due to back injury (10). Thus do they become more tolerant of their back pain episodes during their career or manage appropriately their underlying injury as to not let this injury impact significantly on their training and performance.

\section{Objectives}

The principal aim of this study was to investigate the major rowing injuries seen at a single high performance rowing sport program over a 5 years training period and establish if any relationship exists between these injuries and the competition level of the rower. The underlying hypothesis is that by the time athletes reach interna- 
tional level they are less likely to miss training time for lower back injuries but more likely to have the considered elite level injury of a rib stress fracture.

\section{Patients and Methods}

The South Australian Sports Institute (SASI) is part of the Australian high performance sports network with rowing being one of the principal high performance sports program at the Institute. In a high performance program athletes will receive scholarships to develop and compete in their chosen sport, in this case rowing. Athletes, as well as receiving scholarships, are also transferred into the SASI to train in their respective international high performance crews. Athletes can be categorized into developing (national level) athletes and athletes that compete at open world and Olympic titles (international level). This study involves all rowing athletes selected and/or trained at SASI for the period 20092013. Athletes that compete at open world titles and/or Olympic Games in any given season are denoted international level athletes for that season and subsequent seasons where they remain competing at international level. Rowers who do not compete at open international level but have a SASI high performance rowing scholarship are denoted national level athletes. The number and category (national or international) of athlete was recorded for each year (2009-2013) of the rowing SASI program. Scholarships are offered on a calendar year basis so a scholarship for a year is denoted as a single training year. The total number of training years for national and international rowers can also be calculated. The medical and screening records of all rowers in the SASI rowing program were retrospectively analysed by the author. In addition at SASI all athletes that have an injury that involves the athlete losing training time are recorded and an electronic form is produced which notifies the injury to Rowing Australia for recording and monitoring. Thus there were in effect 3 methods of obtaining the relevant data. For this purpose and subsequent analysis ethics approval was obtained through the Australian Institute of Sport Ethics committee network all injuries that involved the athlete missing 5 or more days from training were denoted as a significant injury. Training was defined for this study as being able to train on the water. Medical illnesses were not included in the analysis. The diagnosis of the injury was recorded. Subsequently the principle injuries analysed where lower back injuries (defined as lower back pain causing the rower to cease training) and rib stress injuries (defined as chest wall pain investigated with bone scan and/or MRI scan to diagnose rib stress injury and causing the athlete to cease training) Chest wall injuries found not to be rib stress injuries and Thoracic spine injuries were considered and recorded as a separate category. In any training year each athlete could only be recorded as having a single injury for a single injury category for that training year (thus recurrences of the same injury in the same year were not recorded). The athlete could however have a different injury in the same training year that was recorded. They also could have a subsequent injury in a different year and this was recorded. To assess the principle hypothesis of whether lower back injuries were more common in national rowers when compared to international rower's statistical analysis (chi squared testing) was used. This compared these groups with the number of back injuries causing training time loss of greater than 5 days with the total number of training years and for number of rowing athletes for each respective category (national or international rower). This procedure was also repeated for rib stress injuries. A p value of less than 0.05 was set as the significant value.

\section{Results}

In the years 2009-2013 at SASI there were 12 international rowers completing 35 total training years. There were 45 national rowers completing 97 total training years. With respect to injuries there were 41 injuries causing greater than 5 days of training time lost in 36 rowers. 32 of these $41(79 \%)$ injuries were considered to be a consequence of overuse with the rest being traumatic injuries (trauma being cycling accidents). Thus 21\% of all SASI high performance rowing program injuries is a consequence of cross-training cycling accidents. There were overall 32 overuse injuries in 27 rowers in 132 training years. Thus $47 \%$ of SASI rowers experienced an overuse injury in the 5 year study period with approximately 1 overuse injury for every 4 training years. The injuries and rowing categories are denoted in Table 1 . With respect to number of training years a national level rower was much more likely to have a lower back injury causing greater than 5 days of training time lost compared to an international rower chi value 3.84, $\mathrm{P}=0.05$. This did not reach significance when the number of athletes with back injury was included in the chi test $1.48, \mathrm{P}=0.2$. With respect to number of athletes an international rower was much more likely to have a rib stress injury causing greater than 5 days of training time lost compared to an national rower chi value 3.96, $\mathrm{P}=0.04$. This did not reach significance when the number of training years was analysed but did demonstrate a trend chi test 2.54, $\mathrm{P}=0.1$. All of the fractures and concussion and the neck sprain all were caused by non-rowing activity-cycling accidents. The brackets figure is the number of athletes and is only presented if there were subsequent injuries in rowers in a later year that resulted in a difference between number of injuries and number of athletes.

Finally this study demonstrates that national level rowers (27 overuse injuries in 22 athletes) have a trend towards more overuse injuries than international level athletes ( 5 overuse injuries in 5 athletes) chi test Value $2.57, \mathrm{P}=0.1)$. The imaging for the two rib stress injuries are shown in Figures 1 - 2. 


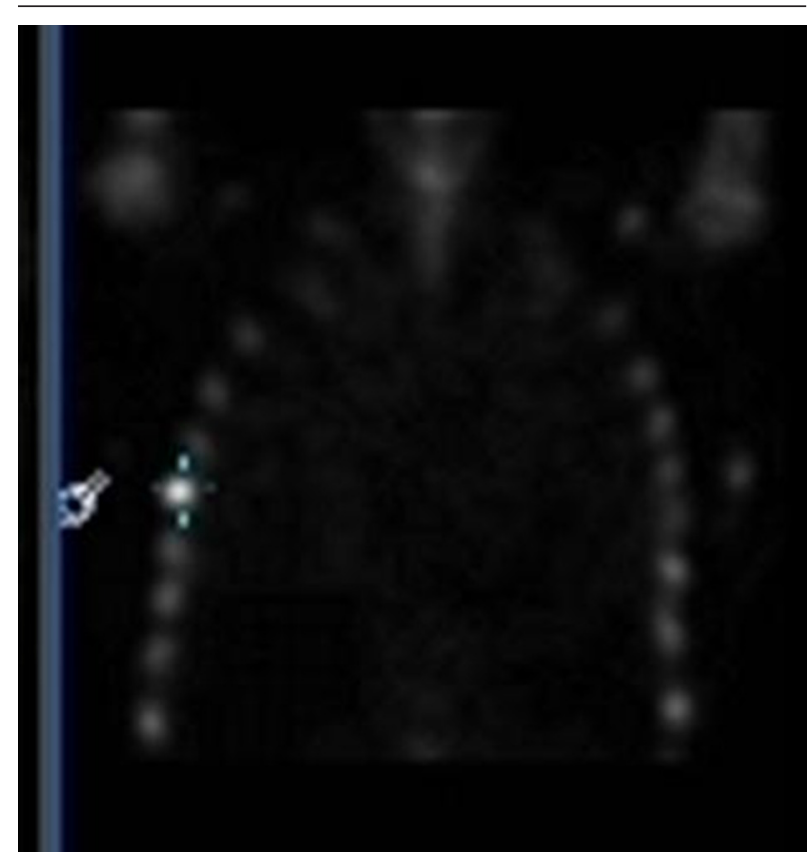

Figure 1. Rib Stress Fracture Posterolateral rib 11-Diagnosed by MRI an Unusual Fracture Considered to be a Consequence of a Boat Position Change

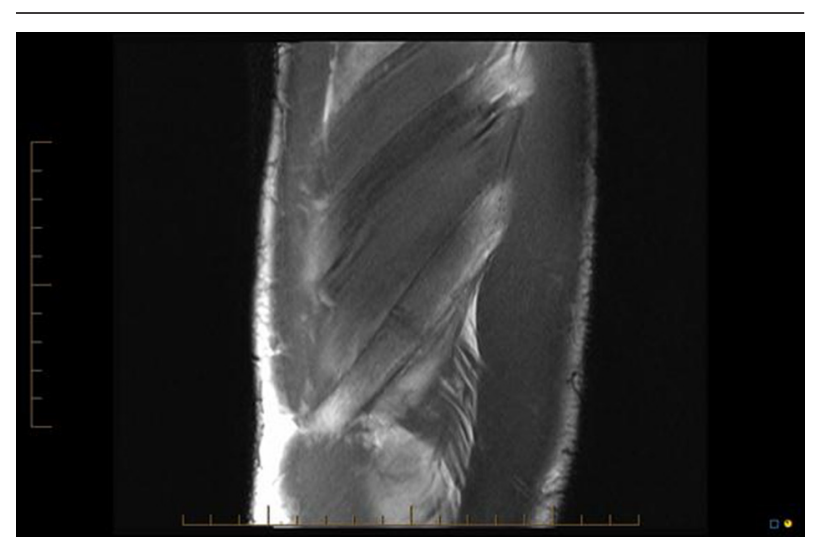

Figure 2. Multiple rib Stress Injuries in an International Level Rower-Diagnosed by Bone Scan a Sudden Increase in Rowing Intensity and Training was Considered to be the Primary Risk as the Athlete was Playing "Catch up" After Completing University Exams.

\section{Discussion}

The most common injuries to cause training time loss in rowing are lower back and chest wall injuries $(1,3,9)$. This study of injuries from a single high performance program on national and international rowers confirms these assertions. In addition, trauma related injuries from principally cycling accidents (21\% of all injuries in this study) and high hamstring tendinopathy are the other major injuries causing rowing training time lost and in this respect have not been previously described as being common injuries of rowers. However the principal findings of our study is that back pain, principally lower
Table 1. Injuries and Categories Causing Greater Than 5 Days Training Loss of National and International Rowers in a Single High Performance Program ${ }^{a}$

\begin{tabular}{lcc}
\hline $\begin{array}{l}\text { Injuries causing }>\text { 5 days train- } \\
\text { ing loss }\end{array}$ & National & International \\
\hline Lower back pain & $15(11)$ & 1 \\
Rib stress & 1 & 2 \\
Thoracic spine/Chest wall & 2 & 0 \\
Wrist tendinopathy/tendinitis & 1 & 0 \\
Finger injury & 1 & 0 \\
Hamstring tendinopathy/Ischio- & $4(3)$ & 1 \\
gluteal bursitis & & \\
Achilles paratendonitis & 0 & 1 \\
Shoulder tendinopathy & 1 & 0 \\
\hline Hip FAI/Labrum/Chondral & 2 & 0 \\
\hline Neck sprain & 1 & 0 \\
\hline Fractures/Contusions & 5 & 2 \\
Concussion & 1 & 0 \\
\hline
\end{tabular}

a All of the fractures and concussion and the neck sprain all were caused by non-rowing activity-cycling accidents. The brackets figure is the number of athletes and is only presented if there were subsequent injuries in rowers in a later year that resulted in a difference between number of injuries and number of athletes.

back pain, is associated with an increased number of national level rowing injuries requiring greater than 5 days training loss compared to international level rowing injuries $(\mathrm{P}=0.05)$. In contrast Figure 2 : Multiple rib stress injuries in an international level rower-diagnosed by bone scan. A sudden increase in rowing intensity and training was considered to be the primary risk as the athlete was playing "catch up" after completing university exams. rib stress injury is associated with an increased number of international level rowing injuries having greater than 5 days training loss compared to national level rowing injuries $\mathrm{P}=0.04$. In a previous review it has been stated that low back injuries have the highest incidence of injury in rowing but rib stress fractures cause the most time lost, that is, the highest prevalence (3). This study partly reinforces this with total numbers demonstrating the high incidence of lower back injuries in rowers. In this studied 5 years period low back injuries, it accounted for nearly $50 \%$ of all injuries, where time lost from training was greater than 5 days, from overuse rowing injuries (cycling/trauma injuries excluded) but this was principally in the developing athlete rather than the international level athlete. Some risk factors for lower back injuries in rowers have been identified. An increased number of low back injuries in rowers have been associated with increased time spent on ergometer training (11). In preventing these low back injuries that may have been precipitated by ergometer training it is recommended that slide based rather than stationery ergometer rowing is used (12) considered as this reduces 
compressive forces in the lumbar spine (7) and bending forces in the ribs (13). At SASI all ergometers during the study period were slide based. Fatigue is also considered a risk factor for lower back injuries in rowers $(14,15)$ as is hyperflexion of the lumbar spine $(7,16)$ and irregular or poorly developed breathing patterns affecting respiratory muscles which are lumbar pain stabilizers $(17,18)$ and rowing technique especially in the catch position $(14,19)$. Rib stress injuries were first described as affecting elite level rowers in the sports medicine literature in the 1990's (20) and were considered to be a consequence of imbalance on the chest wall of active muscle contraction $(8,21)$. Since then it has been considered that these injuries are associated with elite level rowing but no study, to the authors knowledge, exists that compares rib stress injuries in international and national level rowers. It is considered that the pathogenenesis of these injuries includes a sudden increase in amount of rowing $(1,8,9)$ and in our study 2 athletes attained rib stress fractures after attending intensive training camps where the composition of training was changed to be more intense with longer rowing pieces both of which are considered risk factor $(1,13)$. A change in technique is also considered a risk factor for rib stress injury $(12,13)$ and this is certainly the case for our other rib stress fracture where a previous injury involved her to catch up time and instruction to stop trunk lateral flexion during the catch phase of the stroke. A conclusion from this study, but with extremely limited numbers; and while caution should be used if this information is used to modify or change rowing programs, is that rib stress injuries probably represent overuse injuries. It is considered that these injuries result where a rower is literally on the edge with their training program and are subsequently tipped over the edge and suffer stress injury. An international rower is probably more likely to be on this training/injury edge than a national level developing rower. Thus even minimal change in activity (intensity or length,) or technique, has the potential to push the rower over the edge into the realms of a painful rib stress injury. To explain why lower back injuries affect more national level rowers when compared to international rowers requires some speculation. It may be considered that by the time rowers reach international level they have devised management plans for their lower backs that include rowing technique efficiency, avoidance of certain aggravating factors and short term treatment/management for any lower back pain flares so as to avoid significant training time loss. In some respect the international gets used to lower back pain and does not allow this to cause training time loss. Evidence for this includes the prevalence of back injuries with one study demonstrating over $80 \%$ of female rowers having lower back pain (20) and another study demonstrating that college athletes entering rowing program with preexisting lower back pain were less likely to miss training time due to lower back injury compared to rowers without pre-existing back injury (10). This study cannot refute or confirm this tolerance of low back pain assertion. Another consideration as to why international rowers having less back pain than their national rower counterpart could be due to lessening of risk factors as the rower moves forwards and develops in the high performance program. In this manner technique is coached and improves including trunk wall movement, breathing and weights techniques. Also fitness improves and thus fatigue resistance increases as well as only training on slide based ergometers. Also with more sports medicine and sports science and coaching resources working in a coordinated fashion being placed at the higher end of a higher performance program, this results in a better identification, understanding and management of injury risk such as sudden training changes, technique changes, gradual introduction of any changes in weights or ergometer training as well as early intervention and management of developing problems. This study obviously concludes that more of these resources need to be placed at the developing athlete level to identify and prevent injury rather than relying on the Darwinian approach of the survival of the fittest. Which sports performance program can do this will likely have a larger pool of athletes to choose from to compete at the international level. Weaknesses of this study should be pointed out. Retrospectively, the method of detecting injuries limited numbers thus making statistical tests less robust and all athletes are from a single high performance program. These factors combined or in isolation make this study less reliable in making any strong assertions. However in contrast to this there is limited studies on this topic lower back and rib stress injuries in rowers in the literature making this a valuable contribution though obviously more research needs to be undertaken.

Lower back injuries are a significant cause of training time lost in rowers. These injuries are much more likely to occur in national level rowers when compared to international level rowers. In contrast rib stress injuries are associated with international compared to national level rowers. Cycling injuries accounted for $21 \%$ of all injuries resulting in significant time loss from training in this study on rowers in a high performance program.

\section{Acknowledgements}

A thanks to the SASI Director (Mr Wes Battams) and administration for their support for this study. A special thank you to the SASI coaches over the 5 years of this study Mr Jason Lane (Head Coach), Mr Zoltan Shepherd, Mr Adam Vine-Hall and Ms Christine McLaren another thanks to Rowing Australia, in particular Mr Ivan Hooper, for their vigilance and foresight at keeping injury identification and management at the forefront of an elite sports program. Also thanks to Dr. Adrian Esterman from the University of South Australia for his highly valued statistical advice. 


\section{References}

1. Hickey GJ, Fricker PA, McDonald WA. Injuries to elite rowers over a 10-yr period. Med Sci Sports Exerc. 1997;29(12):1567-72.

2. Smoljanovic T, Bojanic I, Hannafin JA, Hren D, Delimar D, Pecina M. Traumatic and overuse injuries among international elite junior rowers. Am J Sports Med. 2009;37(6):1193-9.

3. Rumball JS, Lebrun CM, Di Ciacca SR, Orlando K. Rowing injuries. Sports Med. 2005;35(6):537-55.

4. Roy SH, De Luca CJ, Snyder-Mackler L, Emley MS, Crenshaw RL, Lyons JP. Fatigue, recovery, and low back pain in varsity rowers. Med Sci Sports Exerc. 1990;22(4):463-9.

5. Teitz CC, O'Kane J, Lind BK, Hannafin JA. Back pain in intercollegiate rowers. Am J Sports Med. 2002;30(5):674-9.

6. Maurer M, Soder RB, Baldisserotto M. Spine abnormalities depicted by magnetic resonance imaging in adolescent rowers. $A m$ J Sports Med. 2011;39(2):392-7.

7. Morris FL, Smith RM, Payne WR, Galloway MA, Wark JD. Compressive and shear force generated in the lumbar spine of female rowers. Int J Sports Med. 2000;21(7):518-23.

8. Christiansen E, Kanstrup IL. Increased risk of stress fractures of the ribs in elite rowers. Scand J Med Sci Sports. 1997;7(1):49-52.

9. McDonnell LK, Hume PA, Nolte V. Rib stress fractures among rowers: definition, epidemiology, mechanisms, risk factors and effectiveness of injury prevention strategies. Sports Med. 2011;41(11):883-901.

10. O'Kane JW, Teitz CC, Lind BK. Effect of preexisting back pain on the incidence and severity of back pain in intercollegiate rowers. Am J Sports Med. 2003;31(1):80-2.

11. Wilson F, Gormley J, Gissane C, Simms C. The effect of rowing to exhaustion on frontal plane angular changes in the lumbar spine of elite rowers. J Sports Sci. 2012;30(14):1481-9.

12. Vinther A, Alkjaer T, Kanstrup IL, Zerahn B, Ekdahl C, Jensen $\mathrm{K}$, et al. Slide-based ergometer rowing: effects on force production and neuromuscular activity. Scand J Med Sci Sports. 2013;23(5):635-44.

13. Warden SJ, Gutschlag FR, Wajswelner H, Crossley KM. Aetiology of rib stress fractures in rowers. Sports Med. 2002;32(13):819-36.

14. Caldwell JS, McNair PJ, Williams M. The effects of repetitive motion on lumbar flexion and erector spinae muscle activity in rowers. Clin Biomech (Bristol, Avon). 2003;18(8):704-11.

15. Fulton RC, Strutton PH, McGregor AH, Davey NJ. Fatigue-induced change in corticospinal drive to back muscles in elite rowers. Exp Physiol. 2002;87(5):593-600.

16. Howell DW. Musculoskeletal profile and incidence of musculoskeletal injuries in lightweight women rowers. Am J Sports Med. 1984;12(4):278-82.

17. Manning TS, Plowman SA, Drake G, Looney MA, Ball TE. Intra-abdominal pressure and rowing: the effects of inspiring versus expiring during the drive. J Sports Med Phys Fitness. 2000;40(3):22332.

18. Volianitis S, McConnell AK, Koutedakis Y, Jones DA. The influence of prior activity upon inspiratory muscle strength in rowers and non-rowers. Int J Sports Med. 1999;20(8):542-7.

19. McGregor AH, Anderton L, Gedroyc WM. The trunk muscles of elite oarsmen. Br J Sports Med. 2002;36(3):214-7.

20. Holden DL, Jackson DW. Stress fracture of the ribs in female rowers. Am J Sports Med.1985;13(5):342-8.

21. Karlson KA. Rib stress fractures in elite rowers. A case series and proposed mechanism. Am J Sports Med.1998;26(4):516-9. 